Supporting Information for

On-chip Optical Anodic Stripping with Closed Bipolar Cells and Cathodic Electrochemiluminescence Reporting

Jeronimo Miranda ${ }^{1}$, Nicholas Humphrey ${ }^{1}$, Rowan Kinney ${ }^{1}$, Riley O’Sullivan ${ }^{1}$, Bradley Thomas ${ }^{1}$, Ivan Elias Mondaca Medina ${ }^{1}$, Ryan Freedman ${ }^{1}$, Eli Fahrenkrug, ${ }^{1, *}$

${ }^{1}$ Department of Chemistry \& Biochemistry

Colorado College

14 E. Cache la Poudre Street

Colorado Springs, CO 80903

*Correspondence: efahrenkrug@coloradocollege.edu 


\section{S0. Contents}

This document contains supporting information for the manuscript entitled "On-chip Optical Anodic Stripping with Closed Bipolar Cells and Cathodic Electrochemiluminescence Reporting”. Section 1 details the fabrication procedure used to produce o-AS devices. Section 2 collects additional electrochemical characterization data. 


\section{S1. Sensor Fabrication and Development}

Sensors were designed and dimensioned in AutoCAD software (version 22.0) before being etched via $\mathrm{CO}_{2}$ laser ablation (Dremel Digilab LC-40, $40 \mathrm{~W}$ ) directly onto FTO sheets $(10 \mathrm{x} 10 \mathrm{~cm}, 3.5 \mathrm{~mm}$ thick). FTO sheets were cleaned via sequential sonication in acetone, methanol, and water for 5 minutes each. The laser power and scan rate were tuned to ablate the conductive FTO layer with minimal damage to the underlying glass (Figure S2). A simple continuity measurement via a digital multimeter (Fluke 17B+) was used to confirm sufficient FTO ablation. A single as-purchased FTO sheet could accommodate 10 BPE devices. Etched FTO sheets were sonicated in water for 5 minutes and dried under nitrogen to remove glass debris prior to PDMS adhesion. Figures 1e-g summarize the key fabrication steps of the process. Figure S1 provides additional images and corresponding fabrication detail. Following the laser patterning step, four guide holes were drilled through the FTO sheets using a diamond core drill $(5 \mathrm{~mm})$ and a wet drill press (Dremel, Model 220). Thru holes served to align a custom plastic mold which would define the device reservoirs during PDMS injection and curing (Figures 1f and S1). PDMS was mixed and de-aerated under vacuum at room temperature for $30 \mathrm{~min}$ before injection into the mold via syringe (Figure S1h). The PDMS was allowed to settle at room temperature for several minutes before curing at $95{ }^{\circ} \mathrm{C}$ for $60 \mathrm{~min}$. The mold was carefully disassembled leaving PDMS electrolyte reservoirs precisely positioned on the patterned FTO electrodes with good adhesion between the FTO, glass, and PDMS. The patterned FTO sheets were then diced into individual devices using a glass wet saw. Devices were rinsed in water and dried under nitrogen before use or storage. The footprint of each device was $50 \times 15 \mathrm{~mm}$ with a $\sim 2.5 \mathrm{~mm}$ thick PDMS layer to define the reservoir thickness. Each reservoir was nominally $0.2 \times 0.4 \mathrm{~cm}$ which accounted for a reservoir volume of $0.02 \mathrm{~cm}^{3}$. 

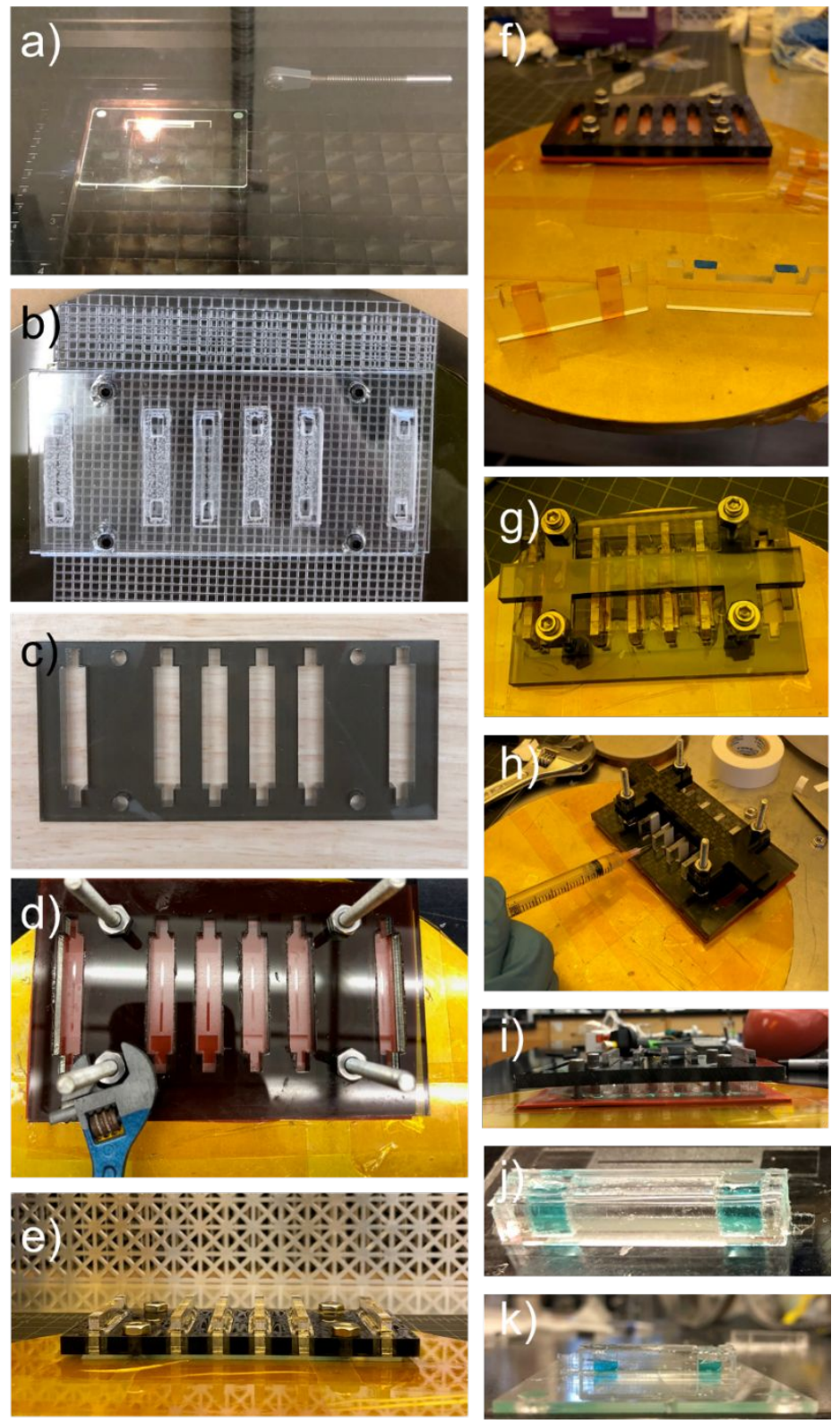

Figure S1. Images from the sensor fabrication sequence. (a) Laser ablation patterning of FTO sheet with a $\mathrm{CO}_{2}$ laser, (b) drilled thru holes in FTO glass for subsequent mold alignment, (c) 0.25 in thick acrylic plastic mold, (d) affixing mold to FTO glass sheet to define regions for PDMS polymerization, (e) side view of mold in (d), (f) plastic tabs inserted into the mold prior to PDMS infiltration to define the outer perimeter of the electrolyte reservoirs, (g) securing the tabs within the mold, (h) injecting liquid PDMS monomer for polymerization, (i) side view of jig in (h), (j) close-up view of a single sensor after removing the mold - electrolyte reservoirs are filled with colored dye for clarity, and (k) side-view of sensor in (j). 

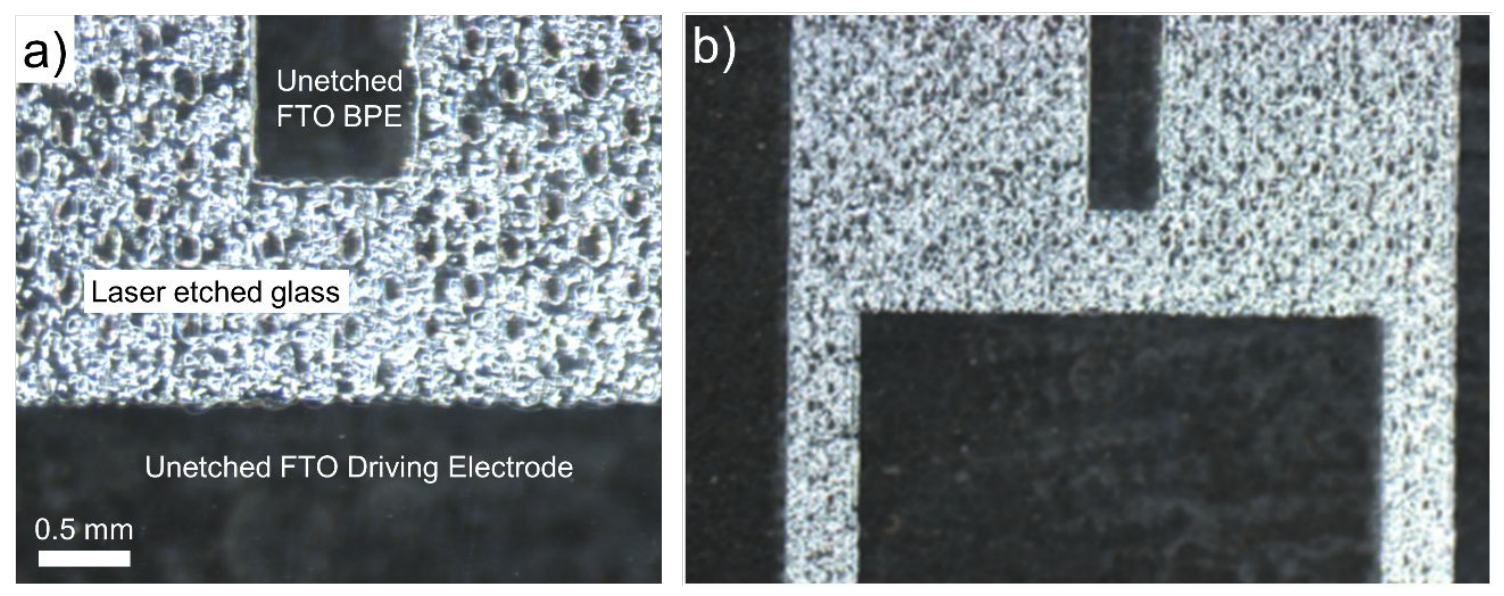

Figure S2. Optical micrographs of laser ablated FTO on glass at (a) 100x and (b) 50x magnification. 


\section{S2. Electrochemical Characterization}

This section collects additional voltammetry experiments on full BPE devices, on solid tin electrodes, in $\mathrm{N}_{2}$ purged solutions, and in variable $\mathrm{pH}$ solutions for comparison.

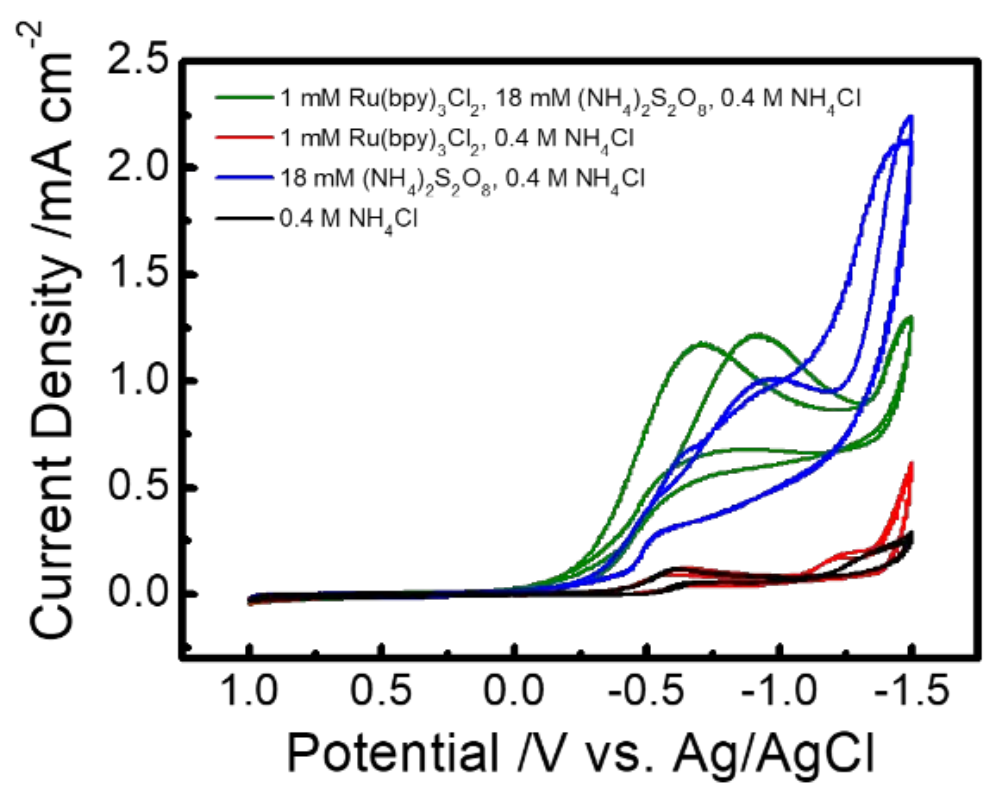

Figure S3. Cyclic voltammetry on GC in a non-buffered solution $(\mathrm{pH} \sim 2)$ of $1 \mathrm{mM} \mathrm{Ru}(\text { bpy })_{3}{ }^{2+}, 18 \mathrm{mM}$ $\left(\mathrm{NH}_{4}\right)_{2} \mathrm{~S}_{2} \mathrm{O}_{8}$ and $0.4 \mathrm{M} \mathrm{NH} \mathrm{Cl}_{4} \mathrm{Cin} 1: 1 \mathrm{H}_{2} \mathrm{O}-\mathrm{MeCN}$. Scan rate was $0.025 \mathrm{~V} / \mathrm{s}$. 

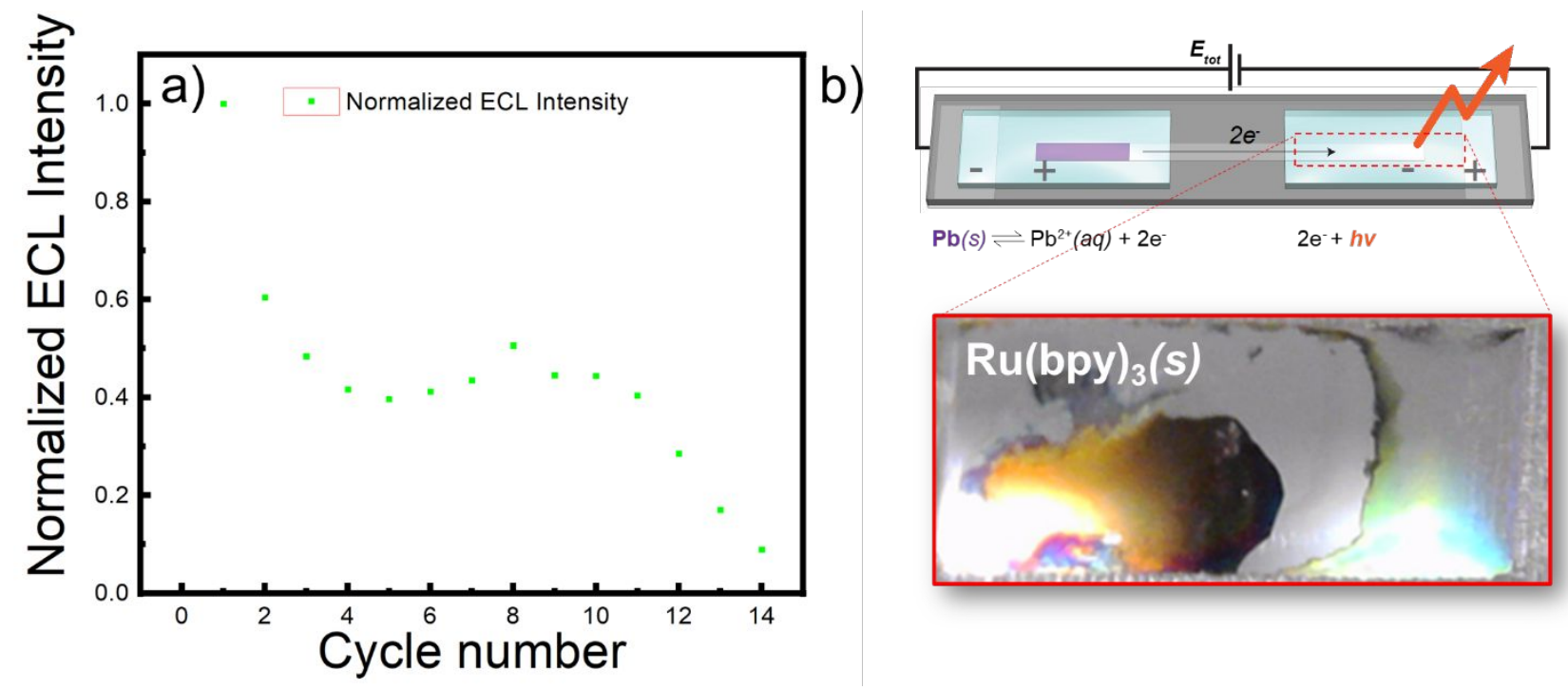

Figure S4. (a) Normalized ECL intensity on GC electrode for first 14 cycles. (b) Cartoon schematic of oAS chip during ECL emission along with optical micrograph collected after 50 cycles from the surface of the FTO BPE in the reporting reservoir. Solution: $1 \mathrm{mM} \mathrm{Ru}(\mathrm{bpy})_{3}{ }^{2+}, 18 \mathrm{mM}\left(\mathrm{NH}_{4}\right)_{2} \mathrm{~S}_{2} \mathrm{O}_{8}$ and $0.4 \mathrm{M} \mathrm{NH}_{4} \mathrm{Cl}$ in $1: 1 \mathrm{H}_{2} \mathrm{O}-\mathrm{MeCN}$. Scan rate was $0.025 \mathrm{~V} / \mathrm{s}$ from 1.0 to $-1.5 \mathrm{~V}$. 


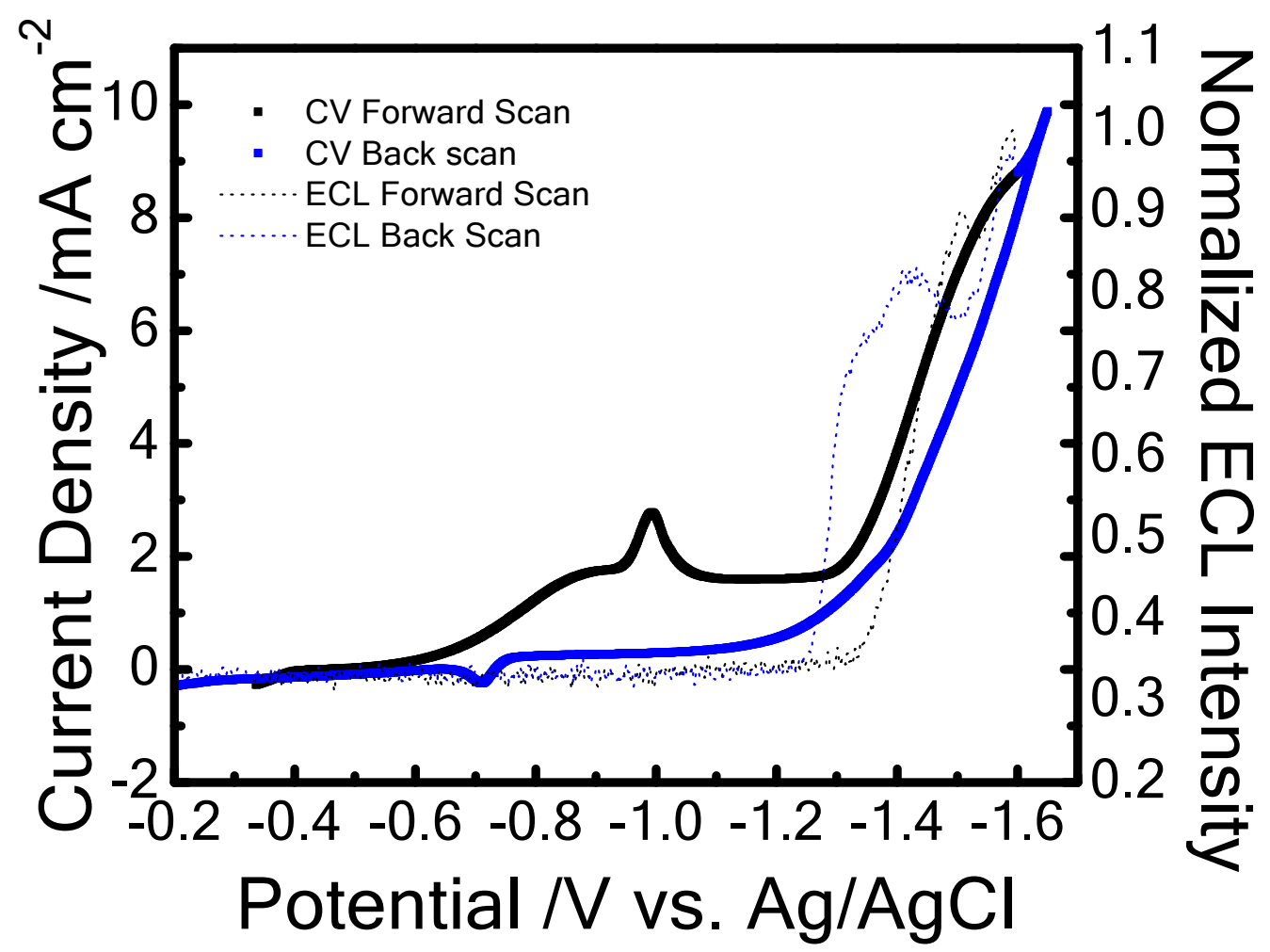

Figure S5. Cyclic voltammetry collected on pure $\mathrm{Sn}^{0}$ electrodes while monitoring ECL emission intensity as a function of applied potential. Tin electrodes were cleaned by rinsing in water prior to use. Scan rate was $0.025 \mathrm{~V} / \mathrm{s}$. Solution included $1 \mathrm{mM} \mathrm{Ru}(\text { bpy })_{3}{ }^{2+}, 18 \mathrm{mM}\left(\mathrm{NH}_{4}\right)_{2} \mathrm{~S}_{2} \mathrm{O}_{8}$ and $0.4 \mathrm{M} \mathrm{NH}{ }_{4} \mathrm{Cl}$ at $\mathrm{pH}=8.0$ in $1: 1 \mathrm{H}_{2} \mathrm{O}-\mathrm{MeCN}$. 


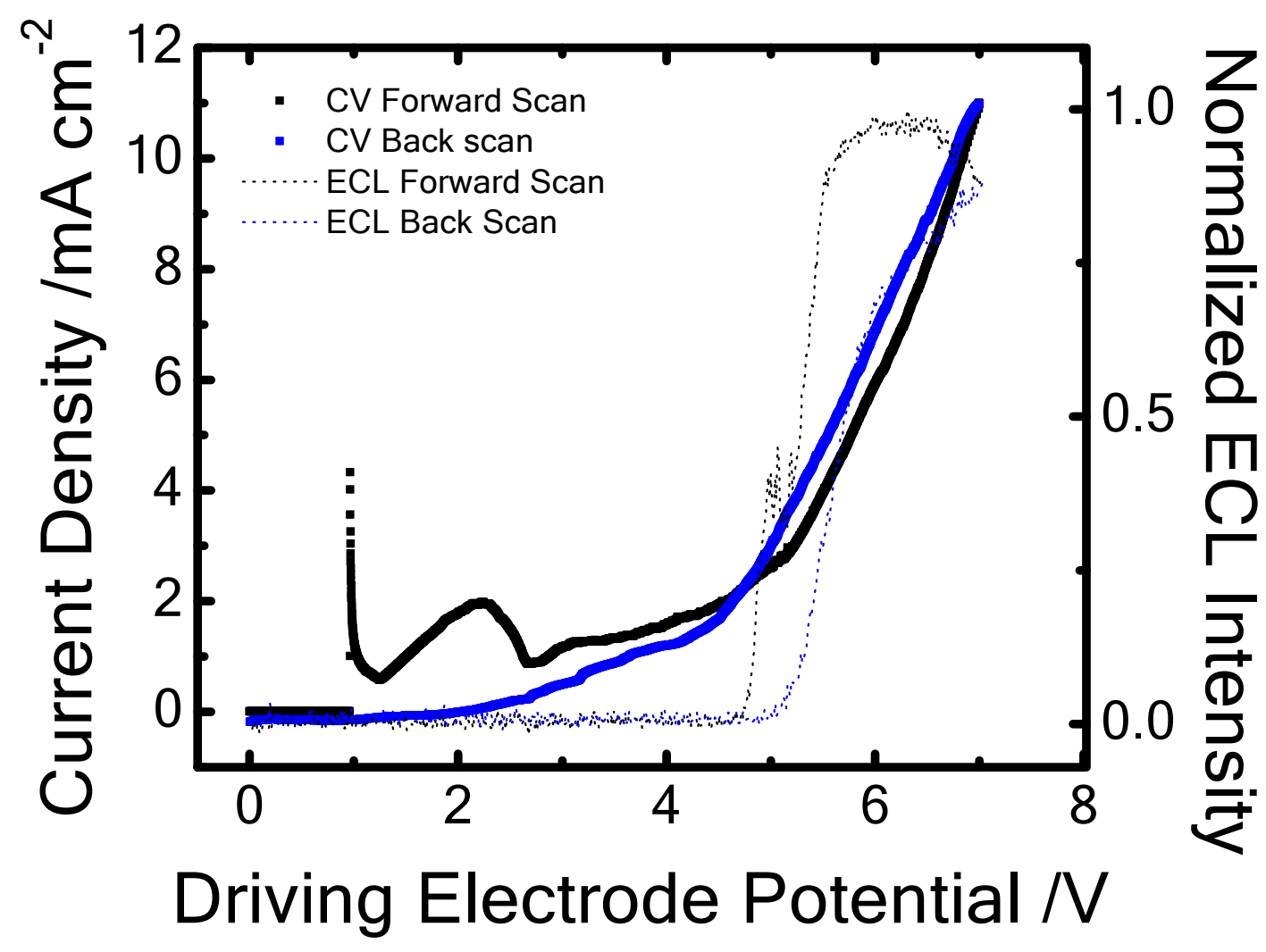

Figure S6. Cyclic voltammetry combined with normalized ECL emission intensity on FTO for a full BPE sensor device during the stripping event. Prior to voltametric analysis, $\mathrm{Pb}^{0}$ was plated on the cathodic pole of the BPE for 1 min from a solution of $\mathrm{Pb}\left(\mathrm{NO}_{3}\right)_{2}$. During voltammetry, the sample reservoir was still charged with the aqueous $\mathrm{Pb}\left(\mathrm{NO}_{3}\right)_{2}$ solution while the reporting reservoir was charged with the typical ECL solution: $1 \mathrm{mM} \mathrm{Ru}(\text { bpy })_{3}{ }^{2+}, 18 \mathrm{mM}\left(\mathrm{NH}_{4}\right)_{2} \mathrm{~S}_{2} \mathrm{O}_{8}$ and $0.4 \mathrm{M} \mathrm{NH}_{4} \mathrm{Cl}$ in 1:1 $\mathrm{H}_{2} \mathrm{O}-\mathrm{MeCN}$. Scan rate was 0.025 $\mathrm{V} / \mathrm{s}$. Stainless steel electrodes were used during this particular experiment to minimize FTO degradation at large potentials. 


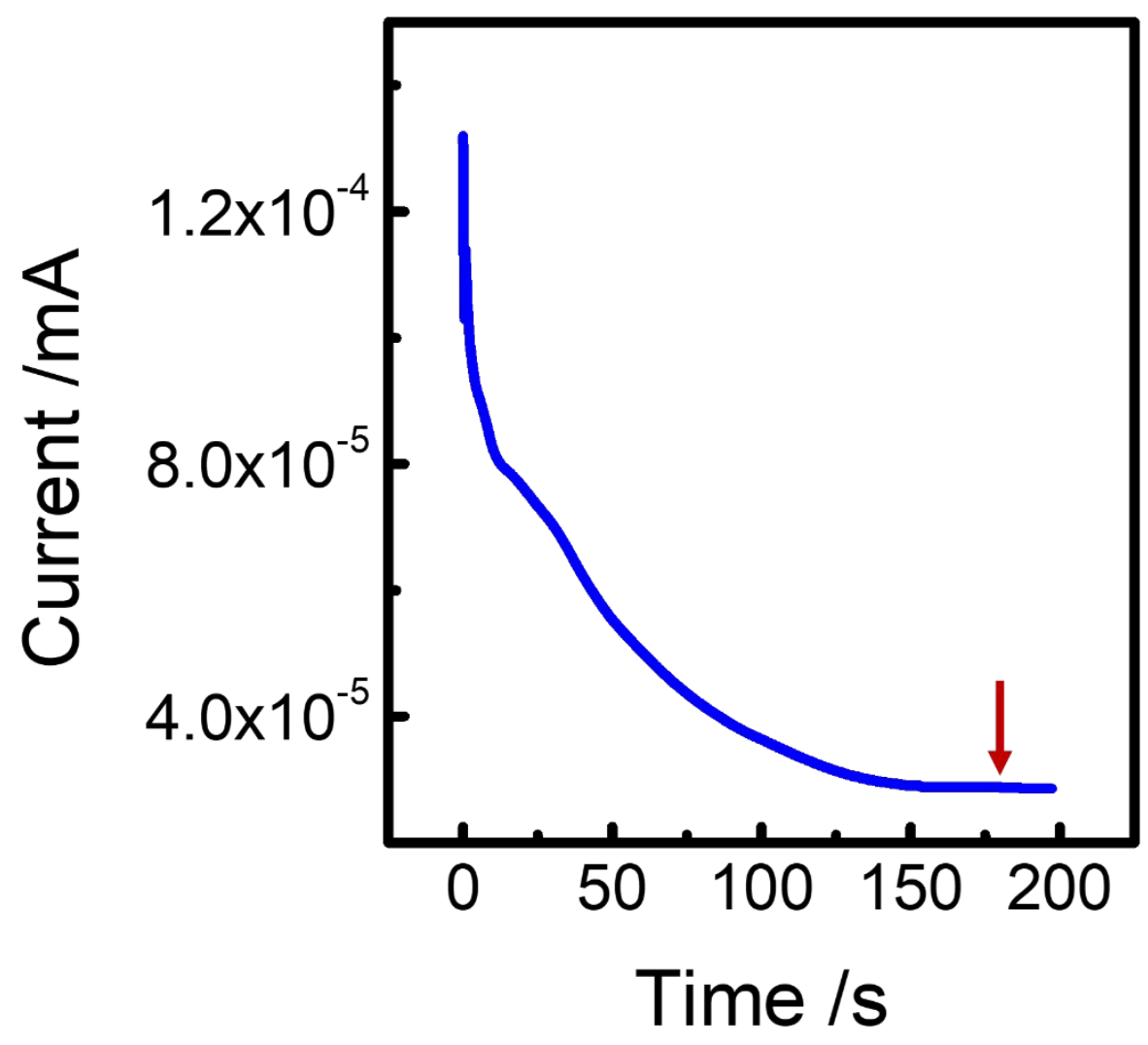

Figure S7. Chronoamperometric trace collected from a full BPE device operating potentiostatically at 3.5 $\mathrm{V}$ for $200 \mathrm{sec}$. The sample reservoir contained $1 \mathrm{ppm}$ aqueous $\mathrm{Pb}\left(\mathrm{NO}_{3}\right)_{2}$. The detection reservoir contained the typical ECL solution: $1 \mathrm{mM} \mathrm{Ru}(\text { bpy })_{3}{ }^{2+}, 18 \mathrm{mM}\left(\mathrm{NH}_{4}\right)_{2} \mathrm{~S}_{2} \mathrm{O}_{8}$ and $0.4 \mathrm{M} \mathrm{NH}_{4} \mathrm{Cl}$ in $1: 1 \mathrm{H}_{2} \mathrm{O}-\mathrm{MeCN}$. The reservoir containing $1 \mathrm{ppm} \mathrm{Pb}^{2+}$ was $\sim 0.02 \mathrm{~cm} 3$ in volume which accounted for $\sim 9.6 \times 10^{-11}$ moles of $\mathrm{Pb}^{2+}$. Assuming $100 \%$ Faradaic efficiency and $2 \mathrm{e}-$ per mol $\mathrm{Pb}^{2+}$, this equates to a theoretical charge of $1.9 \times 10^{-}$ ${ }^{5} \mathrm{C}$. The integrated chronoamperometric trace yielded $1.4 \times 10^{5} \mathrm{C}$ over $200 \mathrm{sec}$ which accounts for $\sim 75 \%$ of the total $\mathrm{Pb}$ in the reservoir. The red arrow in this trace indicates the 3 min plating duration used throughout the text. 